\title{
Heart Rate Variability in a Study on Reiki Treatment
}

\author{
Elisabeth Pizzinato, Joop Muller*, Gerhard Lingg, David Dapra, Harald Lothaller and \\ Peter Christian Endler
}

Interuniversity College for Health and Development, Graz / Castle of Seggau, Austria

\begin{abstract}
Objective: The objective of this work was to determine any changes in HRV (heart rate variability) using shorttime measurements (140 seconds) in a quasi-experimental therapeutic application study on Reiki.

Method: HRV was determined using a ready at hand electrocardiogram device the size of a cellular phone, which requires a measuring time of 140 seconds and electrode contact only with the finger tips. Measurements were performed on healthy test subjects, before and after a defined control rest period and a defined test intervention period (Reiki treatment). 27 test subjects were enrolled.

Results: SDNN (the standard deviation of all heartbeat intervals in ms) and TP (total power of heartbeat interval variability in the frequency range $0.003-0.4 \mathrm{~Hz}$ in $\mathrm{ms}^{2}$ ) were together interpreted as an indicator of test subjects' autonomic nervous activity and as a measure of their ability to cope with demands on their health (regulatory capacity). These values increased both in the control $(\mathrm{p}<0.05)$ and in the test intervention period $(\mathrm{p}<0.01)$. However the increase was more marked after the Reiki intervention (57.8\%/81.7\%) than it was after the control rest period $(19.6 \% / 42.8 \%)$ (interactions: $\mathrm{p}<0.01 / \mathrm{p}>0.05$ ). The LF/HF ratio (sympathico-vagal balance) was interpreted as a measure of the balance between activation and relaxation. No changes in the LF/HF ratio were observed in the course of the control or the test intervention period $(\mathrm{p}>0.05)$.

Conclusion: Both control rest and Reiki treatment had a favourable effect on heart rate variability, but the effect of Reiki treatment was markedly stronger. The measurement device used seems to be a promising tool for practical application studies of this kind.
\end{abstract}

Keywords: HRV, electrocardiogram, Reiki treatment, SDNN.

\section{INTRODUCTION}

In a healthy organism every heart beat differs from the preceding one by minimal deviations in time. A healthy heart does not beat with clockwork regularity but rather in a flexible rhythm. This flexibility, which can be measured in terms of HRV (heart rate variability) [1] (Fig. 1), is observed particularly in phases of rest. Extreme rigidity of heart beat is often associated with a pathological condition [2].

The variability of the heart rate evidently comes about through the interplay between parasympathetic and sympathetic nervous activity. HRV has been used as a non invasive diagnostic method since the mid-1960s. Initially introduced in obstetrics as a parameter for assessing risk to unborn life, its range of application today extends to stress and regeneration research as well as amateur and professionallevel sports. Determination of heart rate variability is regarded as a promising method of assessing an individual's current health and coping status [4]. It is therefore also used in the study of therapeutic applications and therapy evaluation [5-13].

This paper presents the results of an application study on Reiki treatment. Reiki is a method rediscovered by the

*Address correspondence to this author at the Interuniversity College for Health and Development, Graz / Castle of Seggau, Austria;

Tel: +43 3164238 13; Fax: +43 316426708 ;

E-mail: college@inter-uni.net
Japanese buddhist monk Mikao Usui at the beginning of the 20 th century which is aimed at activating or transferring "life energy" in order to improve a person's well-being, prevent disease, heal or attain higher levels of consciousness. The technique comprises attunement exercises and the laying on of hands on certain parts of the body. Reiki is practised in particular for relaxation, stress relief and pain regulation [14]. A Cochrane meta-analysis has shown Reiki and related methods to be effective [15], while other reviews have criticized some/many/some of the larger clinical studies on this topic on methodological grounds [16]. A study on autonomic nervous system changes during Reiki treatment reported promising, though not fully conclusive results [17].

The research questions pursued were as follows:

- Does HRV change under the influence of a defined rest period (control rest)?

- Does HRV change under the influence of a defined one-time intervention (test intervention)?

- Are there between-period differences?

\section{MATERIALS AND METHODS}

The design was that of a quasi-experimental (controlled) application study. The study design was approved by the ethics committee of the Interuniversity College. 


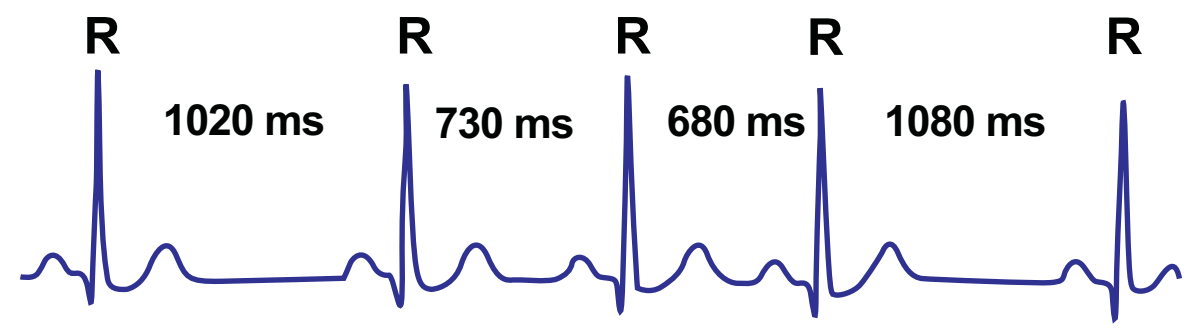

Fig. (1). Example of a sequence of heart beats, with slightly different intervals between R-waves (quoted from [3]). For further explanation see text.
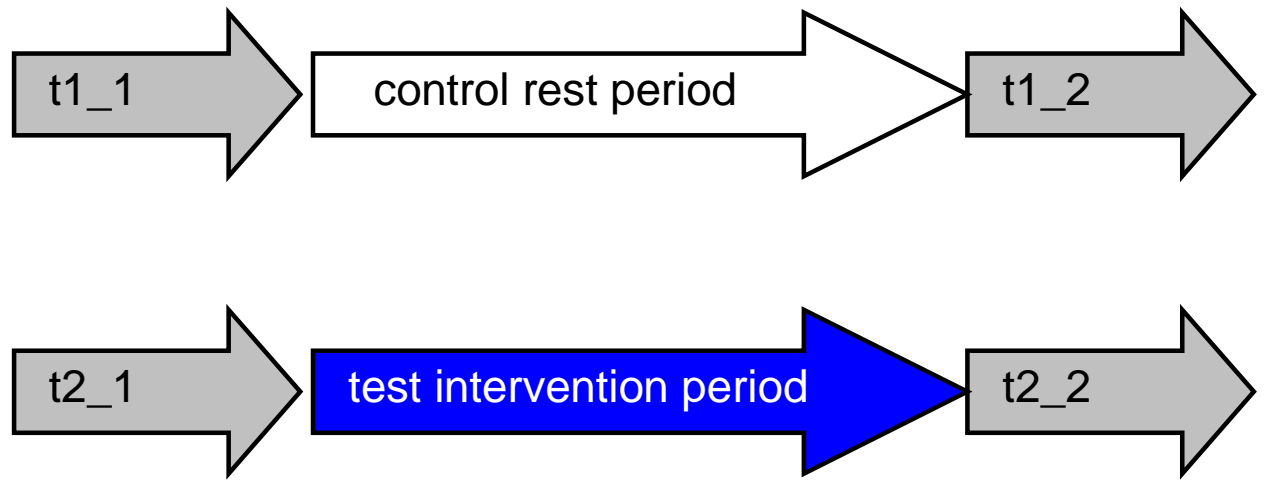

Fig. (2). Sequence of measurements and control or intervention periods. See text for further explanation.

The following parameters were used to describe the status of test subjects' autonomic nervous activity:

- SDNN, the standard deviation (i.e. the square root of the variance) of all RR-intervals (see Fig. 1) in ms, used as an overall measure of heart rate variability across all frequency ranges.

- TP, total power of RR-interval variability in the frequency range $0.003-0.4 \mathrm{~Hz}$ in $\mathrm{ms}^{2}$, used as a supplementary measure (which necessarily correlates strongly with SDNN).

Parameters used to measure parasympathic activation:

- $\quad \mathrm{HF}$ (high frequency power, $0.151-0.4 \mathrm{~Hz}$, in $\mathrm{ms}^{2}$ )

- $\mathrm{HF} \%$ (proportion of HF in relation to TP)

Parameters reflecting sympathetic activation (amongst other processes)

- LF (low frequency power, $0.04-0.15 \mathrm{~Hz}$, in $\mathrm{ms}^{2}$ )

- $\mathrm{LF} \%$ (proportion of LF in relation to TP)

Parameter of sympathico-vagal balance:

- $\mathrm{LFms}^{2} / \mathrm{HFms}^{2}$ ratio

Furthermore, heart rate (HR, in bpm) was measured. No attempt was made to calculate very low frequency power VLF $(0.003-0.039 \mathrm{~Hz})$ from the data of this short term electrocardiogram.

SDNN and TP (overall autonomic nervous status) were interpreted as a measure of test subjects' ability to cope with demands on their health (regulatory capacity) [4]. In preparatory studies performed by the team, mean SDNN ranged about 30 to $50 \mathrm{~ms}$ in various groups of healthy volunteers and TP about 1100 to $1500 \mathrm{~ms}^{2}$. A rest period of several minutes led to no changes or to an increase in SDNN (range about 0 to $10 \mathrm{~ms}$ difference) and TP (range 0 to
$400 \mathrm{~ms}^{2}$ ). In volunteers with an initial SDNN $>75 \mathrm{~ms}$, the rest period led to a decrease in SDNN and TP (in preparation for publication).

The LF/HF ratio (sympathico-vagal balance) was interpreted as a measure of the balance between activation and relaxation [4]. In preparatory studies performed by the team, mean $\mathrm{LF} / \mathrm{HF}$ ratio ranged about 1.0 to 2.0 in various groups of healthy volunteers. A rest period led to no changes or to a decrease in the LF/HF ratio (range about 0 to 0.5 ) (in preparation for publication).

Measurements: HRV parameters were determined using a ready at hand electrocardiogram device (UBW device, IMI company, Liechtenstein) roughly the size of a cell phone. Measurements were performed with test subjects seated while resting the tips of both index and both middle fingers on the device electrode over a 140 second interval. If the device indicated insufficient electrode contact, the test subject's finger tips were wetted prior to measurement. The data delivered by the device used were cross-checked against and found to be compatible with the output of a standard various other HRV device.

Intervention and Test Subjects: The study was aimed at determining the influence of a "Reiki" treatment [14-17] performed by an experienced Reiki practitioner. 27 test subjects with about as many females (13) as males (14) were enrolled. Participants consented to take part in "a scientific study on possible effects of Reiki direct treatment on heart rate variability".

Procedure: A preliminary measurement (not in the protocol) was carried out to familiarise the test subject with the experimental setup. Then, two measurements (" 1 " and " 2") were performed on each test subject at each of two sessions (" $\mathrm{t} 1$ " and " $\mathrm{t} 2$ "), namely before and after the control rest period (t1) and before and after the test intervention period (t2) (Fig. 2). Sessions t1 and t2 took place on two 
Table 1. Values Found for the Control Rest Period. See Text for Further Explanation

\begin{tabular}{|c|c|c|c|}
\hline & Pre & p & Post \\
\hline \hline SDNN & $40.9 \pm 12.7$ & $<0.05$ & $48.9 \pm 12.9$ \\
\hline TP & $1122.4 \pm 833.9$ & $<0.05$ & $1603.3 \pm 793.5$ \\
\hline HF & $363.5 \pm 285.2$ & $<0.05$ & $531.4 \pm 441.1$ \\
\hline HF\% & $33.7 \pm 17.2$ & $>0.05$ & $33.0 \pm 23.2$ \\
\hline LF $\%$ & $356.3 \pm 301.7$ & $>0.05$ & $523.7 \pm 395.2$ \\
\hline LF/HF & $33.2 \pm 14.0$ & $>0.05$ & $33.7 \pm 17.8$ \\
\hline HR & $1.6 \pm 1.6$ & $>0.05$ & $1.7 \pm 1.6$ \\
\hline
\end{tabular}

Table 2. Values Found for the Test Intervention Period. See Text for Further Explanation

\begin{tabular}{|c|c|c|c|}
\hline & Pre & p & Post \\
\hline \hline SDNN & $42.2 \pm 11.9$ & $<0.01$ & $66.6 \pm 28.3$ \\
\hline TP & $1309.2 \pm 755.1$ & $<0.01$ & $2378.4 \pm 1712.0$ \\
\hline HF & $425.5 \pm 370.9$ & $<0.01$ & $627.3 \pm 490.6$ \\
\hline HF\% & $31.5 \pm 17.9$ & $>0.05$ & $29.2 \pm 19.5$ \\
\hline LF & $445.6 \pm 334.1$ & $<0.01$ & $859.3 \pm 827.2$ \\
\hline LF\% & $34.1 \pm 16.6$ & $>0.05$ & $33.9 \pm 13.2$ \\
\hline HR & $1.9 \pm 2.3$ & $>0.05$ & $2.1 \pm 2.1$ \\
\hline
\end{tabular}

subsequent days at identical times of day for each participant. The time interval between_1 and_2 was 40 minutes.

Conditions during the control rest period and the test intervention period were otherwise identical, so that it can be assumed that if there were any unspecific influences, relating for example to the person conducting the experiment or her relationship with the test subject, they cancelled each other out. Thus, any differences observed between the control regimen and the test intervention in the degree of change occuring during the experiment could be attributed to the test intervention.

Evaluation: The data found were evaluated by analysis of variance with repeated measures of the parameters in a pre-post design and the treatments as independent variables. This procedure allows to identify differences between preand post-measurements for each treatment condition and in addition whether the treatment conditions differ in pre-post changes.

$\mathrm{LF} / \mathrm{HF}$ ratios were calculated on the basis of the individual measurements and not on the basis of LF and HF means. Results with an error probability $\mathrm{p}<0.05$ were considered significant.

\section{RESULTS}

Table 1 shows the values for the parameters described in Methods for measurement points t1_1 (immediately before the control rest period) and t1_2 (after the control rest period) (mean \pm standard deviation), and the p-value obtained (significance).

Table 2 shows the values obtained immediately before and after the test intervention.

SDNN and TP values increased both in the control period $(19.6 \%, \mathrm{p}<0.05 / 42.8 \%, \mathrm{p}<0.05)$ and in the test intervention period $(57.8 \%, \mathrm{p}<0.01 / 81,7 \%, \mathrm{p}<0.01)$. However, the increase was more marked in the test than in the control rest period (interactions: $\mathrm{p}<0.01 / \mathrm{p}>0.05$ ). While the values before the intervention and rest periods do not differ $(\mathrm{p}>0.05)$, the values differ significantly in the post measurement $(\mathrm{p}<0.01 / \mathrm{p}<0.05)$.

No changes in the LF/HF ratio were observed in the course of the control or the test intervention period $(\mathrm{p}>0.05)$.

\section{DISCUSSION}

In this study on Reiki treatment SDNN and TP were used as a global measure of autonomic nervous activity and as an indicator of test subjects' ability to cope with demands on their health (regulatory capacity) [4]. Before the control rest and before the test intervention period, mean values $(40.9 \mathrm{~ms}$ $/ 1,122.4 \mathrm{~ms}^{2}$ and $42.2 \mathrm{~ms} / 1,309.2 \mathrm{~ms}^{2}$, respectively) were within the range expected from the literature ${ }^{4}$ and from various preliminary studies performed by the team (in preparation for publication). SDNN and TP values increased both in the control $(\mathrm{p}<0.05)$ and in the test intervention period $(\mathrm{p}<0.01)$. However the increase was more marked after the test intervention $(57.8 \% / 81.7 \%)$ than it was after the control rest period $(19.6 \% / 42.8 \%)$. The increase was more marked in the test than in the control rest period (interactions: $\mathrm{p}<0.01 / \mathrm{p}>0.05$ ).

The $\mathrm{LF} / \mathrm{HF}$ ratio (sympathico-vagal balance) was interpreted as a measure of the balance between activation and relaxation [4]. Here too, mean baseline values (1.6 in the control group, 1.9 in the test group) were within the expected range, classifying as a mild sympathicotony according to literature data. No changes in the LF/HF ratio were observed in the course of the control or the test intervention period ( $\mathrm{p}$ $>0.05)$. 
The design of the study (control rest period versus test intervention period under otherwise comparable conditions) was such that any unspecific influences (person conducting the experiment, her relationship with the test subject) can be assumed to have cancelled each other out. Thus, any differences observed between the control regimen and the test intervention in the degree of change occurring during the experiment should be attributable to the test intervention.

\section{CONCLUSION}

Simple rest and Reiki treatment both have a favourable effect on autonomic nervous activity, but the effect of Reiki treatment appears to be markedly stronger.

The present investigation is to be regarded as a pilot study. However, the results are in line with the literature in that they indicate that heart rate variability may be a useful tool to determine effects of interventions, including CAM [513]. The measurement device used seems to be a promising tool for practical application studies of this kind.

\section{CONFLICT OF INTEREST}

The authors confirm that this article content has no conflicts of interest.

\section{ACKNOWLEDGEMENT}

Declared none.

\section{LIST OF ABBREVIATIONS}

\begin{tabular}{|c|c|c|}
\hline RV & & heart rate var \\
\hline -wave & $=$ & $\begin{array}{l}\text { peak in the electrocardiogram, caused by } \\
\text { each single heartbeat }\end{array}$ \\
\hline SDNN & $=$ & $\begin{array}{l}\text { standard deviation of all RR-intervals in } \mathrm{ms} \text {, } \\
\text { used as an overall measure of heart rate } \\
\text { variability across all frequency ranges }\end{array}$ \\
\hline$P$ & $=$ & $\begin{array}{l}\text { total power of RR-interval variability in the } \\
\text { frequency range } 0.003-0.4 \mathrm{~Hz} \text { in } \mathrm{ms}^{2} \text {, used } \\
\text { as a supplementary measure (which } \\
\text { necessarily correlates strongly with SDNN) }\end{array}$ \\
\hline $\mathrm{HF}$ & $=$ & $\begin{array}{l}\text { high frequency power, } 0.151-0.4 \mathrm{~Hz} \text {, in } \\
\mathrm{ms}^{2} \text {, parameters used to measure } \\
\text { parasympathic activation }\end{array}$ \\
\hline $\mathrm{HF} \%$ & $=$ & proportion of HF in relation to TP \\
\hline LF & $=$ & $\begin{array}{l}\text { low frequency power, } 0.04-0.15 \mathrm{~Hz} \text {, in } \mathrm{ms}^{2} \text {, } \\
\text { parameters reflecting sympathetic activation } \\
\text { (amongst other processes) }\end{array}$ \\
\hline & & proportion of LF in relation to TP \\
\hline
\end{tabular}

$\mathrm{LF} / \mathrm{HF}=$ ratio or $\mathrm{LFms}^{2} / \mathrm{HFms}^{2}$ ratio $=$ parameter of sympathico-vagal balance

$\mathrm{HR}=$ heart rate, in bpm

$\mathrm{VLF}=$ very low frequency power VLF, $0.003-$ $0.039 \mathrm{~Hz}$

\section{REFERENCES}

[1] Berntson GG, Bigger JT, Eckberg T, et al. Heart rate variability: Origins, methods, and interpretive caveats. Psychophysiology 1997; 34: 623-48.

[2] Moser M, Lehhofer M, Sedminek A, et al. Heart rate variability as a prognostic tool in cardiology: a contribution to the problem from a theoretical point of view. Circulation 1994; 90(2): 1078-82.

[3] Mück-Weymann M. Herzratenvariabilitäts-Biofeedback. Forum Stressmedizin. Available at: www.stressmedizin.de, 2007; vol. I, pp. 1-7.

[4] Wittling W, Schweiger E. Diagnostik der Herzratenvariabilität. Einblicke in die autonom-nervöse Regulation von Stressverarbeitung, Befindlichkeit, Verhalten und Gesundheit. Forschungsbericht, Zentrum für Neuropsychologische Forschung, Universität Trier 2007.

[5] Bettermann H, Cysarz D, Kümmell HC, et al. Heart rate variability: how to assess effects of mild therapies on autonomic control in small groups of mild and borderline hypertensives? Hypertension 2000; 35: e6.

[6] Agelink MW, Sanner D, Eich H, et al. Does acupuncture influence the cardiac autonomic nervous system in patients with minor depression or anxiety disorders? Fortschritte Neurologie und Psychiatrie 2003; 71: 141-9.

[7] Li Z, Wang C, Mak A, et al. Effects of acupuncture on heart rate variability in normal subjects under fatigue and non-fatigue state. $\mathrm{J}$ Appl Physiol 2005; 94: 633-40.

[8] Trappe HJ. The effects of music on the cardiovascular system and cardiovascular health. Heart 2010; 96(23): 1868-71.

[9] Routledge FS, Campbell TS, McFetridge-Durdle JA, Bacon SL. Improvements in heart rate variability with exercise therapy. Can J Cardiol 2010; 26(6): 303-12.

[10] Mazzeo AT, La Monaca E, Di Leo R, et al. Heart rate variability: a diagnostic and prognostic tool in anesthesia and intensive care Acta Anaesthesiol Scand 2011; 55(7): 797-811.

[11] Field T, Tai Chi. Research review. Complement Ther Clin Pract 2011; 17(3): 141-6.

[12] Mishra N, Muraleedharan KC, Paranjpe AS, et al. An exploratory study on scientific investigations in homeopathy using medical analyzer. J Altern Complement Med 2011; 17: 705-10.

[13] Courtney R, Cohen M, van Dixhoorn J. Relationship between dysfunctional breathing patterns and ability to achieve target heart rate variability with features of "Coherence" during biofeedback. Altern Ther Health Med 2011; 17(3): 38-44.

[14] Pschyrembel ${ }^{\circledR}$, Naturheilkunde und alternative Heilverfahren. De Gruyter, Berlin: New York 2006.

[15] So PS, Jiang Y, Qin Y. Touch therapies (Healing Touch, Therapeutic Touch and Reiki) for pain relief in adults (Review). The Cochrane Collaboration: The Cochrane Library 2012.

[16] Lee MS, Pittler MH, Ernst E. Effects of reiki in clinical practice: a systematic review of randomised clinical trials. Int J Clin Pract 2008; 62(6): 947-54.

[17] Mackay N, Hansen S, McFarlane O. Autonomic nervous system changes during Reiki treatment: a preliminary study. J Altern Complement Med 2004; 10(6): 1077-81. 